\title{
OSWALD VEBLEN
}

\section{BY DEANE MONTGOMERY}

Professor Oswald Veblen died at his summer home in Brooklin, Maine, on August 10,1960. He was survived by his wife, Elizabeth Richardson Veblen, and by four sisters and one brother. He was born in Decorah, Iowa, on June 24,1880 , and was the oldest of a family of eight children, four girls and four boys.

He was one of the most influential mathematicians of this century, partly through his contributions to the subject and partly through the effect of his remarkable judgment and force of character. He had an unfailing belief in high standards and was prepared to stand for them irrespective of his own comfort or convenience. He contributed in a decisive way not only to excellence in mathematics but to excellence in American scholarship in general. He was one of those mainly responsible for carrying Princeton forward from a slender start to a major mathematics center. There can be but very few who play such a large part in the development of American and world mathematics.

Shortly after his death the faculty and trustees of the Institute for Advanced Study joined in writing of him as follows:

"We are acutely conscious of the loss to the Institute and to the world of learning of a major figure.

"Oswald Veblen was of great influence in developing the Institute as a center for postdoctoral research, but this was only a part of a career extending back for half a century to the time when scholarly work was in its infancy in Princeton and the United States. His effect on mathematics, transcending the Princeton community and the country as a whole, will be felt for decades to come; but his interest and influence went far beyond his own field and he was a powerful force in establishing the highest academic standards in general.

"He loved simplicity and disliked sham. He placed the standing of the Institute ahead of his personal convenience. He possessed the art of friendship, and his assistance was decisive for the careers of dozens of men. His helping hand is remembered with gratitude in many academic communities all over the world.

"We are grateful for his great strength and courage, for his unusual wisdom, for his unflinching integrity and honesty, for his uncompromising ideals, and, not least, for his generous friendship."

Received by the editors October 6, 1962 . 
In 1955 on the occasion of the twenty-fifth anniversary of the founding of the Institute, Mr. Herbert Maass, then Chairman of the Board of Trustees, stated, "... we were the fortunate beneficiaries of the services of Professor Oswald Veblen, formerly of Princeton University, who aided greatly in the establishment of the School of Mathematics and who ever since has been a tower of strength in maintaining the high standards originally set for the Institute."

Although Veblen had far more friends and admirers than most men, it was of course inevitable that there was occasional friction with those who either did not understand or who found it expedient not to follow his shining academic ideals. Anyone familiar with the academic scene knows that the pressures against quality are formidable, and that the battle for excellence has no end. Excuses for weakness and pettiness in academic matters are so familiar as to be trite and are usually presented under the pretense of one or another noble motive, but for Veblen there did not exist a valid excuse for a choice of anything but the best.

Veblen was a grandson of Thomas Anderson Veblen and Kari Thorsteinsdatter Bunde Veblen who moved in 1847 from Valdres, Norway, to Ozaukee County, Wisconsin, on the western shore of Lake Michigan, just north of Milwaukee. (Wisconsin became a state in 1848.) They lived here and in the nearby counties of Sheboygan and Manitowoc until they moved in 1865 to a farm in Rice County, Minnesota, about fifty miles south of Minneapolis. They had twelve children, and the family lived under the rugged pioneer conditions of the Northwest at that time. One of their children was Thorstein Bunde Veblen (1857-1929) who became a distinguished economist and social theorist. Another of their children was Andrew Anderson Veblen (1848-1932). In 1877 Andrew Veblen married Kirsti Hougen (1851-1908) and to them Oswald Veblen was born in 1880. Kirsti Hougen emigrated in 1856 from Hallingdal, Norway, to a farm in Western Goodhue County, Minnesota. The Hougen and Veblen families lived on farms not far apart in the vicinity of Nerstrand, Minnesota. In this area Norwegian settlers were in an overwhelming majority and even now Norwegian is often spoken when neighbors meet.

At the time Oswald Veblen was born, his father was teaching mathematics and English at Luther College in Decorah, Iowa. The father did graduate work at Johns Hopkins from 1881 to 1883 and in 1883 moved with his family to Iowa City, Iowa, and began teaching mathematics and physics at the State University of Iowa. It was in Iowa City that Oswald Veblen received his grade school and high school education in the public schools and where he graduated with a 
B.A. degree in 1898 at the University. As a student he won a prize in mathematics and another in sharpshooting. During these early years he took a trip by boat down the Iowa and Mississippi rivers and he often spoke of this trip with pleasure. The year following his graduation he stayed on at the University as an assistant in physics and conducted some of his father's courses when his father was ill with typhoid fever. Immediately after this year he went to Harvard where he graduated with a second B.A. degree in 1900 .

He went to Chicago in 1900 to begin his graduate work and at this time Thorstein Veblen was an assistant professor of political science there. At Chicago he took courses in mathematics from Bolza, Maschke, and E. H. Moore, and he also took a course in philosophy from John Dewey. He received his Ph.D. in 1903 with a thesis on the foundations of geometry written under E. H. Moore. He continued at Chicago for two more years as an associate in mathematics. The University of Chicago had opened in 1890 and quickly assembled a strong faculty in mathematics. It was about this time that it first became possible to obtain good graduate training in mathematics in the United States; before this period it had been necessary for Americans to travel to Europe for advanced work in mathematics. Some of the other mathematics students at Chicago at about this time were Birkhoff, Lennes, and R. L. Moore. Birkhoff took his Ph.D. at Chicago in 1907. R. L. Moore received his Ph.D. under Veblen in 1905. Birkhoff and Moore later taught for a time at Princeton when Veblen was there.

Veblen was brought to Princeton University in 1905 by the then President of the University, Woodrow Wilson and by Dean Henry Burchard Fine, as one of the new "preceptor guys"; these were being added to increase the academic strength of Princeton. He was promoted to full professor in 1910 and Henry Burchard Fine Professor in 1926. In 1932 he was appointed a professor at the Institute for Advanced Study which had just been founded and located in Princeton. He kept his professorship at the Institute until he was made emeritus in 1950. After that he continued his constructive interest in mathematics and the Institute through contact with his colleagues and through his position as a trustee of the Institute.

His contributions to Princeton University and to the Institute like those to the academic scene in general were enormous. He was one of the main forces in building the University mathematics department. Some of his own students who were added to the University faculty were J. W. Alexander, A. Church, and T. Y. Thomas. He played an important part in the appointment of Lefschetz and other 
distinguished men, and in the building of Fine Hall, the mathematics building at the University donated by the Jones family. At the Institute he was largely responsible for the selection of its early mathematics faculty, which, in addition to himself, contained Alexander, Einstein, Morse, von Neumann, and Weyl. Moreover, he was largely responsible for determining the Institute's policy of concentrating on postdoctoral work, his ideas on the subject having taken form by his experiences at the University. He was a trustee of the Institute from its early days until his death (for his last few years he was an honorary trustee). He played a large part in arranging the purchase by the Institute of the tract of land it now occupies.

It was at his suggestion that the National Research Council started granting postdoctoral fellowships in mathematics in 1924. This suggestion has had a great influence on the careers of scores of young men. The committee of selection for many years consisted of Birkhoff, Bliss, and Veblen. Funds for fellowships of this kind now come from the National Science Foundation. This suggestion of his was typical of his constant helpfulness and encouragement to others, especially to young men and to the talented wherever found. His work on the committee for selecting fellows was done conscientiously and thoroughly. His file contains a carbon copy of a three-page letter written to the other committee members shortly before one of their annual meetings. His letter mentions that he had spent three full days studying the applications, that he had written to many colleagues in this country and abroad for their advice on many of the applicants, and that he had consulted about the matter with several people in Princeton. He went on to make a preliminary ordering with a few comments on his estimate of each of the candidates. It is clear that the decisions of the committee were not made in a casual manner. His ability to detect talent was well known, and it was evidently based in part on a thorough search.

In the years immediately after Hitler's rise to power Veblen was a central figure in helping to relocate many distinguished foreign mathematicians in the United States. His help was mainly on a personal basis, but partly as a member of committees. His files contain a large correspondence on this subject with men from all parts of this country and many countries abroad. There are numerous letters to and from Harold Bohr and G. H. Hardy, both of whom were active in this direction. Years later he occasionally received words of thanks from men he had forgotten he had helped. Subsequently he was influential in founding Mathematical Reviews and devoted a great deal of energy in this direction. 
Veblen was a great admirer of England and continental Europe. At the same time he was an equally great admirer of all that was good in the American tradition and was often quick to comment on American achievements.

In writing obituaries of Dean Fine of Princeton and G. D. Birkhoff of Harvard he revealed something of himself, and many of the things he said of them could well be said of him. His comment on an address by Birkhoff was as follows:

"Among the unconscious revelations of the address on 'Fifty years of American mathematics,' one of the most vivid is that of the depth and sincerity of Birkhoff's devotion to the cause of mathematics, and particularly of 'American mathematics.' This, along with his devotion to Harvard, was always a primary motive. It may be added that a sort of religious devotion to American mathematics as a 'cause' was characteristic of a good many of his predecessors and contemporaries."

His opening remarks in his obituary of Dean Fine are given below:

"Dean Fine was one of the group of men who carried American mathematics forward from a state of approximate nullity to one verging on parity with the European nations. It already requires an effort of the imagination to realize the difficulties with which the men of his generation had to contend, the lack of encouragement, the lack of guidance, the lack of knowledge both of the problems and of the contemporary state of science, the overwhelming urge of environment in all other directions than the scientific one. But by comparing the present average state of affairs in this country with what can be seen in the most advanced parts of the world, and extrapolating backwards, we may reconstruct a picture which will help us to appreciate their qualities and achievements."

In 1928-1929 Veblen was an exchange professor at Oxford and in 1932 lectured at Göttingen, Berlin, and Hamburg. He and his wife traveled to Europe frequently.

He was president of the American Mathematical Society during 1923-1924. At this time the Society was in a financial crisis and Veblen was very effective in helping to meet this crisis and to establish an endowment fund. He was president of the International Congress held at Harvard in 1950. This honor touched him very deeply and he evidently took it to be, as it was, a recognition of the tremendous effort and devotion he had given to mathematics and scholarship. His brief 
remarks in opening the congress are well worth reading for their wisdom and insight. He received honorary degrees from Oslo, Oxford, Hamburg, Chicago, Princeton, Edinburgh, and Glasgow. He was an honorary member or fellow of learned societies in the United States as well as a number abroad including Denmark, England, France, Ireland, Italy, Peru, Poland, and Scotland.

Veblen married Elizabeth Richardson of Dewsbury, Yorkshire, England, in 1908. They met when she was visiting her brother, Owen Richardson, who was teaching physics at Princeton at that time. Later Owen Richardson was a professor at King's College, London University, and was awarded a Nobel Prize. Veblen was related by marriage to another Nobel Prize winner, Clinton Joseph Davisson, the husband of Mrs. Veblen's sister, Charlotte Richardson.

During the First World War Veblen was a captain and later a major in charge of range firing and ballistic work at a Proving Ground. In the Second World War he helped build up a research team at Aberdeen for work on ballistics.

In the last few years of his life he was partially blind although he retained some peripheral vision. He grew interested in developing devices to help himself and others with a similar affliction to read. One of these devices was put into production by the American Foundation for the Blind. Toward the end of his life he suffered from a strained heart and this finally caused his death. Although these illnesses were discouraging, he remained cheerful and maintained his usual interests and activities on only a slightly reduced scale. His mind and judgment continued to be unusually keen and penetrating, and his conversation was as rewarding as ever.

One of his hobbies was photography and another was a layman's interest in archaeology. Through all of his life he was fond of woods and the outdoors. He and Mrs. Veblen gave a tract of 80 acres to Mercer County, New Jersey, which is called the Herrontown Arboretum and which is intended to provide for walks in a natural wooded section of New Jersey.

Veblen was unusually helpful to other mathematicians, and throughout his life he took a special interest in young mathematicians. $\mathrm{He}$ and his wife were generous with hospitality. Most of the mathematicians and a great many other academic people visiting Princeton during several decades were guests either in their Battle Road home or, in later years, in their home on Herrontown Road.

In spite of his great efforts on behalf of mathematics and scholarship, his own direct contributions were solid and very substantial. One of his earliest papers [2] was on the Heine-Borel Theorem. In it 
he observed that this theorem could be used instead of the pinching process in the proof of some of the theorems on limits and continuity in analysis. This observation was exploited in the book Introduction to infinitesimal analysis, functions of one real variable [15] which he wrote with $\mathrm{N}$. J. Lennes, a book which was quite influential in introducing students to rigorous proofs of the theorems of advanced calculus and elementary real function theory. This subject in this country was a rather new one at the time.

His thesis [5] on the foundations of geometry was the beginning of his first major interest in mathematics. More than that it remained influential in most of his interests throughout his life for almost all of his work was connected with geometry, and in all of it he was greatly concerned with precision and completeness. He had the ability to see the foundations in a clear and relevant way without wandering into ramifications beyond the requirements of mathematics. His thesis contains a footnote thanking his director E. H. Moore and also thanking N. J. Lennes and R. L. Moore for critically reading parts of the manuscript. His axioms were stated in terms of points and order. There were 12 axioms which were proved to be independent and categorical. His thesis led on to a number of papers over the next several years on such related subjects as finite projective geometries and axioms for projective geometry. Perhaps this direction of his interest may be said to have culminated in the two volumes of Projective geometry of which Volume I was written with J. W. Young. Formally, Young is also a joint author of Volume II, but he, in reality, was unable to participate in the writing because of his other duties. These two books were widely read.

Veblen was a firm believer in the abstract approach to mathematics. In his work on geometry he attempted (and in the preface to the second volume of Projective geometry enjoined others) to "not merely prove every theorem rigorously but to prove it in such a fashion as to show in which spaces it is true and to which geometries it belongs." The two volumes on Projective geometry carry out this program in admirable fashion. "All the theorems of Volume I are valid, not alone in the ordinary real and the ordinary complex projective spaces, but also in the ordinary rational space and in the finite spaces." Moreover the list of assumptions under which each theorem is true is stated, and from this the relation between projective geometry and algebraic structure may be discerned.

Along with his interest in the foundations of geometry he developed an interest in algebraic topology, or analysis situs as it was then called and by 1912 was writing papers on this subject. At the time it was 
not widely pursued and it was interesting to hear Veblen's comments on the feelings of the men striking out in this comparatively new field. Veblen's work was of much greater influence in encouraging others in this direction than is generally realized today. His papers and his Colloquium lectures on the subject were influential over many years. These Colloquium lectures were delivered at Cambridge in 1916 and were published in 1922. For many years they remained the best introduction to the subject.

Gradually he became more interested in differential geometry. From 1922 onward most of his papers were in this area and in its connections with relativity. In addition to his papers he wrote three short books on this subject, one of them in collaboration with J. H. C. Whitehead. Throughout all of his work he insisted on clarity. It was this trait which helped put algebraic topology on a firm foundation, for although the subject had already received brilliant contributions from Poincaré and others, some of its tools and concepts remained somewhat vague. His work on axioms for differentiable manifolds and differential geometry contributed directly to the field and helped to create the setting for the lively developments to come. In fact some of the concepts to come can be found in these books. A great deal of his effort for the last several years of his scientific career was spent on spinors. Much of this has never appeared, partly perhaps because of his insistence on clarity and precision.

Veblen remained rather youthful in his point of view to the end, and he was often amused by the comments of younger but aging men to the effect that the great period for this or that was gone forever. He did not believe it. Possibly part of his youthful attitude came from his interest in youth; he was firmly convinced that a great part of the mathematical lifeblood of the Institute was in the flow of young mathematicians through it. He felt too that the main justification for the Institute was in whatever impact it had on the academic scene, especially the American academic scene.

\section{Bibliography of Oswald Veblen}

1. Hilbert's foundations of geometry, Monist 13 (1903), 303-309.

2. The Heine-Borel theorem, Bull. Amer. Math. Soc. 10 (1904), 436-439.

3. Polar coordinate proofs of trigonometric formulas, Amer. Math. Monthly 11 (1904), 6-12.

4. The transcendence of $\pi$ and $e$, Amer. Math. Monthly 11 (1904), 219-223.

5. A system of axioms for geometry, Trans. Amer. Math. Soc. 5 (1904), 343-384. Doctoral dissertation as separate with special title page and "Life."

6. Theory of plane curves in nonmetrical analysis situs, Trans. Amer. Math. Soc. 6 (1905), 83-98. 
7. Definition in terms of order alone in the linear continuum and in well-ordered sets, Trans. Amer. Math. Soc. 6 (1905), 165-171.

8. Euclid's parallel postulate, Open Court 19 (1905), 752-755.

9. The foundations of geometry, Pop. Sci. Mo. (1906), 21-28.

10. The square root and the relations of order, Trans. Amer. Math. Soc. 7 (1906), 197-199.

11. Finite projective geometries (with W. H. Bussey), Trans. Amer. Math. Soc. 7 (1906), 241-259.

12. Collineations in a finite projective geometry, Trans. Amer. Math. Soc. 8 (1907), 366-368.

13. Nondesarguesian and nonpascalian geometries (with J. H. M. Wedderburn), Trans. Amer. Math. Soc. 8 (1907), 379-388.

14. On magic squares, Math. Mag. 37 (1907), 116-118.

15. Introduction to infinitesimal analysis, functions on one real variable (with N. J. Lennes), Wiley, London and New York, 1907, vii +277 pp.; reprinted Stechert, New York, 1935.

16. Continuous increasing functions of finite and transfinite ordinals, Trans. Amer. Math. Soc. 9 (1908), 280-292.

17. On the well-ordered subsets of the continuum, Rend. Circ. Mat. Palermo 25 (1908) 235-236, 397.

18. A set of assumptions for projective geometry (with J. W. Young), Amer. J. Math. 30 (1908), 347-380.

19. Projective geometry, 2 vols. (Vol. 1 with J. W. Young), Ginn, Boston, 1910-18, $\mathrm{x}+342+\mathrm{xii}+511 \mathrm{pp}$. 263.

20. Letter to the editor of the Jahresbericht, Jber. Deutsch. Math. Verein. 19 (1910),

21. The foundations of geometry, with J. W. A. Young, Monographs on Topics of Modern Mathematics, New York, 1911, Chapter I, pp. 1-51.

22. On the definition of multiplication of irrational numbers, Amer. J. Math. 34 (1912), 211-214.

23. Jules Henri Poincaré, Proc. Amer. Philos. Soc. 51 (1912), iii-ix.

24. An application of modular equations in analysis situs, Acta Math. Ser. 214 (1912), 86-94.

25. Decomposition of an n-space by a polyhedron, Trans. Amer. Math. Soc. 14 (1913), 65-72, 506.

26. Manifolds of $n$ dimensions (with J. W. Alexander), Acta Math. Ser. 214 (1913), 163-178.

27. On the deformation of an n-cell, Proc. Nat. Acad. Sci. U.S.A. 3 (1917), 654-656.

28 Rotating bands (with P. L. Alger), J. U. S. Artillery 51 (1919), 355-390.

29. On matrices whose elements are integers (with P. Franklin), Acta Math. Ser. 2

23 (1921), 1-15. Also, with minor changes, in O. Veblen, Analysis situs, 2nd ed., 1931 (no. 30), 170-189.

30. Analysis situs, Amer. Math. Soc. Colloq. Publ. Vol. 5, part 2, 1922, vii +150 pp.; 2nd ed., 1931, x+194 pp.

31. The Riemann geometry and its generalization (with L. P. Eisenhart), Proc. Nat. Acad. Sci. U.S.A. 8 (1922), 19-23.

32. Normal coordinates for the geometry of paths, Proc. Nat. Acad. Sci. U.S.A. 8 (1922), 192-197.

33. Projective and affine geometry of paths, Proc. Nat. Acad. Sci. U.S.A. 8 (1922), 347-350. 
34. Equiaffine geometry of paths, Proc. Nat. Acad. Sci. U.S.A. 9 (1923), 3-4.

35. Geometry and physics, Science 57 (1923), 129-139. Address of vice president AAAS.

36. The intersection numbers, Trans. Amer. Math. Soc. 25 (1923), 540-550. Also, with minor changes, in O. Veblen, Analysis situs, 2nd. ed., 1931 (no. 30), 159-169.

37. The geometry of paths (with T. Y. Thomas), Trans. Amer. Math. Soc. 25 (1923), 551-608.

38. Extensions of relative tensors (with T. Y. Thomas), Trans. Amer. Math. Soc. 26 (1924), 373-377.

39. Invariance of the Poincare numbers of a discrete group, Bull. Amer. Math. Soc. 30 (1924), 405-406.

40. Remarks on the foundations of geometry, Bull. Amer. Math. Soc. 31 (1925), 121-141, AMS retiring presidential address, December 31, 1924.

41. Projective normal coordinates for the geometry of paths (with J. M. Thomas), Proc. Nat. Acad. Sci. U.S.A. 11 (1925), 204-207.

42. Projective invariants of affine geometry of paths (with J. M. Thomas), Acta Math. (2) 27 (1926), 279-296.

43. Invariants of quadratic differential forms (Cambridge Tracts in Math. and Math. Phys., no. 24), Cambridge, 1927, vii +102 pp. Translation into Japanese, Tokyo, 1951, 144.

44. Projective tensors and connections, Proc. Nat. Acad. Sci. U.S.A. 14 (1928), 154-166.

45. Conformal tensors and connections, Proc. Nat. Acad. Sci. U.S.A. 14 (1928), 735-745.

46. Differential invariants and geometry, International Congress of Mathematicians, Bologna, Vol. 1, 1929, pp. 181-189.

47. Generalized projective geometry, J. London Math. Soc. 4 (1929), 140-160.

48. Differential forms; Projection in mathematics; Projective geometry; Encyclopaedia Britannica, 14th ed., London and New York, 1929, Vol. 7, pp. 365-366; Vol. 18, pp. 572-576.

49. Henry Burchard Fine - in memoriam, Bull. Amer. Math. Soc. 35 (1929), 726-730.

50. A generalization of the quadratic differential form, Quart. J. Math. Oxford. Ser. (2) 1 (1930), 60-76.

51. Projective relativity (with B. Hoffmann), Phys. Rev. 36 (1930), 810-822.

52. The department of mathematics, Princeton Alumni Weekly 31 (1931), 633.

53. The significance of Fine Hall, Princeton Alumni Weekly 32 (1931), 112-113. Incorporated in an article entitled, $A$ memorial to a school-teacher.

54. A set of axioms for differential geometry (with J. H. C. Whitehead), Proc. Nat. Acad. Sci. U.S.A. 17 (1931), 551-561.

55. The foundations of differential geometry (with J. H. C. Whitehead), (Cambridge Tracts in Math. and Math. Phys., no. 29), Cambridge, 1932, ix +96 pp. Translation into Japanese by Kentaro Yano, Tokyo, 1950, 104.

56. Projektive Relativitätstheorie (Ergebnisse der Mathematik und ihrer Grenzgebiete, vol. 2, no. 1), Berlin, 1933, v+73 pp.

57. Geometry of two-component spinors, Proc. Nat. Acad. Sci. U.S.A. 19 (1933), 462-474.

58. Geometry of four-component spinors, Proc. Nat. Acad. Sci. U.S.A. 19 (1933), 503-517.

59. Spinors in projective relativity, Proc. Nat. Acad. Sci. U.S.A. 19 (1933), 979-989. 
60. Projective differentiation of spinors (with A. H. Taub), Proc. Nat. Acad. Sci. U.S.A. 20 (1934), 85-92.

61. The Dirac equation in projective relativity (with $\mathrm{A}$. $\mathrm{H}$. Taub and $\mathrm{J}$. von Neumann), Proc. Nat. Acad. Sci. U.S.A. 20 (1934), 383-388.

62. Certain aspects of modern geometry-A course of three lectures ... I. The modern approach to elementary geometry; II. Analysis situs; III. Modern differential geometry, Rice Institute pamphlets 21 (1934), 207-255.

63. Spinors, J. Washington Acad. Sci. 24 (1934), 281-290; Science 80 (1934) 415-419.

64. Formalism for conformal geometry, Proc. Nat. Acad. Sci. U.S.A. 21 (1935), 168-173.

65. A conformal wave equation, Proc. Nat. Acad. Sci. U.S.A. 21 (1935), 484-487.

66. Geometry of complex domains (with J. W. Givens), mimeographed lectures, Princeton, N. J., 1936, iii + 227 pp.

67. Spinors and projective geometry, International Congress of Mathematicians, Oslo, Vol. 1, 1937, pp. 111-127.

68. George David Birkhoff (1884-1944), American Philosophical Society Year Book, 1946, 1947, 279-285; also in Birkhoff, G. D., Collected mathematical papers, Vol. 1, New York, 1950, pp. xv-xxi.

69. Opening Address, Proceedings of the International Congress of Mathematicians, Cambridge, Mass., 1950, Vol. I, 1952, pp. 124-125.

70. Nels Johann Lennes, (with Deane Montgomery), Bull. Amer. Math. Soc., 60 (1954), 264-265.

71. Reviews of books by Bortolotti, Russell, Vahlen, Lechalas, Stolz and Gmeiner Huntington, and Birkhoff in Bull. Amer. Math. Soc., 1905-1924.

INSTITUTE FOR ADVANCED STUDY 